MESSAGE

\title{
From the Executive
}

Mid-year and the cold is settling in. The hype about the introduction of fixed-dose combinations (FDCs) has passed. We have started giving these combinations to the first priority group; so newly diagnosed HIV-infected patients and pregnant women are starting on one tablet once a day. While this is very exciting and without a doubt the way forward, there are still reports of stock-outs of other medications.

The Southern African HIV Clinicians Society is actively engaging and forming links with other Southern African countries. I spent a very fruitful weekend in Harare for the inaugural meeting of the reconstituted Zimbabwean branch. Over 70 keen healthcare workers attended a fullday meeting packed with lots of teaching and discussion. What I personally love about travelling and meeting other HIV clinicians is seeing the same drive and passion to find solutions. We are all part of a massive movement of healthcare workers who simply want solutions to the health crisis. Formal barriers have been broken down as we share what we have done and learn what others are doing.

The ultimate vision of the Society is to engage with all the Ministries of Health in the region and come up with one unified response to HIV and TB.

\section{Francesca Conradie}

President

Southern African HIV

Clinicians Society

fconradie@witshealth.co.za

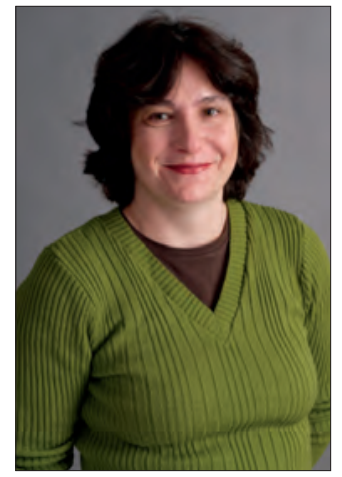

